\title{
Risk of Depression among Early Onset Type 2 Diabetes Mellitus Patients
}

\author{
Baizid Khoorshid Riaz ${ }^{a}$ Shahjada Selim ${ }^{b} \quad$ Megan Neo $^{c} \quad$ Md Nazmul Karim $^{d}$ \\ M. Mostafa Zaman ${ }^{\mathrm{e}}$ \\ aNational Institute of Preventive and Social Medicine, Dhaka, Bangladesh; ${ }^{b}$ Department of Endocrinology, \\ Bangabandhu Sheikh Mujib Medical University, Dhaka, Bangladesh; 'School of Public Health and Preventive \\ Medicine, Monash University, Melbourne, VIC, Australia; ${ }^{\mathrm{d} F a c u l t y}$ of Medicine Nursing and Health Sciences,

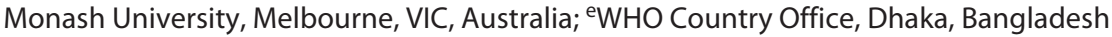

\section{Keywords}

Early onset diabetes mellitus - Depression - Type 2 diabetes mellitus · Hospital Anxiety and Depression Scale

\begin{abstract}
Methodology: Biochemically confirmed type 2 diabetes mellitus (T2DM) patients ( $n=1,114)$ were recruited from the outpatient department of 2 tertiary care hospitals in Dhaka, Bangladesh. Face-to-face interview was conducted using a semi-structured questionnaire containing sociodemographic parameters and relevant information about depression and diabetes. Biochemical test results and treatment-related information were taken from patients' records. The Hospital Anxiety and Depression Scale (HADS) was used to screen all patients for psychiatric manifestation. Those diagnosed by HADS were subsequently reassessed using structured clinical interview for DSM-5 Disorders - Clinician Version. T2DM diagnosed at age $<40$ years were considered as early onset T2DM. Association between age of onset category and depression was assessed using multivariable mixed-effect logistic regression adjusting for random variation of the area of residence and plausible confounders. Results: Around a third of the participants (32.5\%) were diagnosed with T2DM
\end{abstract}

karger@karger.com www.karger.com/dde

Karger $\stackrel{\text { ' }}{5}$
(C) 2021 The Author(s)

Published by S. Karger AG, Basel

This is an Open Access article licensed under the Creative Commons Attribution-NonCommercial-4.0 International License (CC BY-NC) (http://www.karger.com/Services/OpenAccessLicense), applicable to the online version of the article only. Usage and distribution for commercial purposes requires written permission. before the age of 40 years. Early onset T2DM patients were found to have $57 \%$ increase in the risk of developing depression (OR 1.57; 95\% Cl 1.13-2.28; $p=0.011)$ in comparison to those with usual onset T2DM ( $\geq 40$ years). Among other factors a positive family history for diabetes (OR 1.33; $95 \% \mathrm{Cl}$ $1.03-1.78 ; p=0.038$ ), poor glycemic control (OR $1.31 ; 95 \% \mathrm{Cl}$ $1.03-1.68 ; p=0.028$ ), presence of 1 , or more diabetic complications (OR $1.37 ; 95 \% \mathrm{Cl} 1.03-1.78 ; p=0.011$ ) also showed increased risk of depression. Conclusion: Early onset T2DM patients are at greater risk of developing depression. The finding is likely to help in setting preventive strategies aiming to reduce the presence of concomitant depression symptoms among diabetes.

(c) 2021 The Author(s)

Published by S. Karger AG, Basel

\section{Introduction}

Evidence from several epidemiological studies documented increased and significant risk of potential depressive disorders among patients with type 2 diabetes mellitus (T2DM) patients [1-5]. Both the conditions have debilitating effects on their own. Comorbid depression in T2DM exerts greater risk of complications and poorer 
treatment outcome compared to these conditions alone and are likely to incur higher health care costs $[1,6,7]$. Depression in patients with diabetes mellitus (DM) represents a complex, comorbid condition, which is the result of complicated interactions between biopsychosocial and genetic factors. Depression originates as a direct consequence of neurochemical changes with diabetes, which negatively affects health outcomes. The combination of diabetes and depression is associated with decrease in functional abilities and self-care [8-11]. Rustad et al. [12] found that the prevalence of major depression in people with diabetes was $11 \%$, and the prevalence of clinically relevant depression was $31 \%$. DM is a common health problem with extreme medical and economic consequences.

Despite high occurrence of comorbid depression in T2DM patients, depression is often undiagnosed and untreated in primary care settings [13], though the evidence suggests that depression plays an important role in the worsening of diabetes [9] and its importance as a public health problem research in the area have been scarce. Not surprisingly, the precise underlining mechanisms for the relationship between these 2 conditions are yet to be elucidated $[14,15]$.

Studies linking diabetes with depression points toward hyperglycemia as a key contributor of depression $[16,17]$. The counterargument to this conjuncture lies in the differential association with depression in type $1 \mathrm{DM}$ and T2DM patients [18] despite chronic hyperglycemia is common to both. The association of depression between each type of diabetes might be driven by different underlying pathogenesis and may not merely the hyperglycemia itself. Increasing evidence shows that diabetes and depression are independently linked with various biopsychosocial factors that mediate the association between these comorbid conditions $[19,20]$.

The median age of onset of depression, early to the middle 20s [21], and the different management therapy and age of onset for type 1 and 2 diabetes demand 2 separate approaches for the diseases' comorbidity. Type $1 \mathrm{DM}$ appears in childhood and early adulthood demanding daily insulin injections for life, while T2DM appears later in life, in mid-adulthood, demanding diet and lifestyle modifications, oral medication, or insulin injections [22]. Recent studies showed that there are not any common genetic factors to account for the positive association between depression and type $1[23]$ or $2[24,25]$ diabetes.

However, different environmental factors (epigenetic factors) may activate common pathways that promote DM2 and depression in the end. One important factor is a low socioeconomic status that increases the odds for T2DM [26] but also appears to be a cause for depression [27]. The other common causes for DM2 and depression are poor sleep, lack of physical exercises, and diet. Taking into consideration these factors, a key candidate for a common pathway could be the activation and disturbance of the stress system. Chronic stress activates the hypothalamus-pituitary-adrenal axis and the sympathetic nervous system, increasing the production of cortisol in the adrenal cortex and the production of adrenalin and noradrenaline in the adrenal medulla [28]. Chronic hypercortisolemia and prolonged sympathetic nervous system activation promote insulin resistance, visceral obesity and lead to metabolic syndrome and T2DM [29]. On the other hand, chronic stress has behavioral consequences: noradrenaline, cortisol, and other hormones activate the fear system determining anxiety, anorexia, or hyperphagia; the same mediators cause tachyphylaxis of the reward system, which produces depression and cravings for food, other substances, or stress [30]. Excess cortisol disturbs neurogenesis in the hippocampus [31], a region involved in depression as well as in T2DM [32].

It has been suggested that T2DM could be conditioned by depression, anxiety, or anguish [33, 34]; nevertheless, the reason for this association is not clear $[35,36]$. The neurobiological mechanisms that could explain the association between depression and T2DM [37] could include (1) the alterations involved in the metabolism of biogenic amines (serotonin and norepinephrine), from the adrenal-pituitary-hypothalamus axis (by increasing cortisol) $[37,38],(2)$ trophic agents such as brain-derived neurotrophic factor through glycogen synthase kinase-3 (GSK-3) $[39,40]$. The GSK-3 is a serine/threonine protein kinase that mediates the addition of phosphate molecules into serine and threonine amino acid residues. It consists of 2 isoforms, $\alpha$ and $\beta[41,42]$. It is possible that an over activation of GSK-3 plays an important role in the pathogenesis of the development of schizophrenia and mood disorders such as bipolar disorder and major depression in patients with T2DM $[43,44]$.

One of several proposed mechanisms of the link between depression and T2DM is that the perceived burden of the future life with an irreversible, chronic disorder may predispose patients to depression [45]. The cognitive-behavioral model by Moulton et al. [46] suggests that the burden of T2DM leads to negative thoughts about diabetes and low mood. Talbot and Nouwen [14] supported the conjuncture and showed a higher risk of depression in people with the awareness of a diagnosis of diabetes than in people with glucose metabolic disorder
56

Dubai Diabetes Endocrinol J 2021;27:55-65 DOI: $10.1159 / 000515683$
Riaz/Selim/Neo/Karim/Zaman 
or undiagnosed diabetes [47]. Depression in DM may be coincidentally present as they share almost similar lifestyle factors, such as socioeconomic deprivation, smoking, and reduced physical activity and environmental factors [48]. However, all patients with DM do not develop depression [2]. We hypothesize that subgroups in the population with DM based on different sociodemographic and disease characteristic in the context of increased risk of developing depression may provide clue.

Previously, T2DM was considered a disease of older people. Over the past decades, the age of T2DM diagnosis appears to be falling, and it is now increasingly being diagnosed below the age of 40 years [47, 49-51]; there are convincing data which suggesting the occurrence T2DM in younger people and worse overall prognosis of youngonset T2DM compared with type 2 diabetes diagnosed in older age [52-54]. It is also evident that patients with early onset T2DM comprise a distinct and more aggressive phenotype [55]. The knowledge of the relationships between DM and depression would help in setting preventive strategies aiming to reduce the presence of concomitant depression symptoms among diabetes. Our study examines possible relation between time of diabetes onset and risk of depression. This knowledge could provide valuable recommendations for primary care practice on identifying targets of prevention efforts.

\section{Materials and Methods}

A total of 1,114 T2DM patients were recruited from the outpatient department (OPD) of Bangladesh Institute of Research and Rehabilitation in Diabetes, Endocrine and Metabolic Disorder (BIRDEM) and Shaheed Suhrawardy Medical College Hospital, Dhaka. BIRDEM is a central tertiary care hospital of the Diabetic Association of Bangladesh and diabetic patients from all over the country including referred patients from 74 affiliated centers and project hospitals are destined here. Shaheed Suhrawardy Medical College Hospital is a government-funded tertiary teaching hospital. Both the hospitals attract patients with diverse demographic and socioeconomic background from all over the country. Thus, data generated from these hospitals may be considered as a fair reflection of general diabetic population of the country. Patients attending at OPDs of BIRDEM hospital were recruited by cluster sampling. Every data collection day, 2 OPD consultation rooms were randomly selected by lottery out of 13 rooms in the participating hospitals. All the diabetic patients attended the designated room that day were approached to participate in the study, those consented were included in the study. The response rate was $82.8 \%$ among those approached. Patients who had documented overt/ clinical comorbidities such as untreated or uncontrolled hypertension, active symptomatic ischemic heart disease, cardiovascular disease (within 6 months), had stage IV and V CKD had overt, untreated hypothyroidism, were already taking antidepressants for depression and who were taking other psychiatric and psychotropic medications, those who were closely following with a psychiatrist for depression and other diagnosis, with active cancer, on chemotherapy or other modalities of treatment, were on medications for other chronic illness whose side effect is depression/or were taking any drug of abuse, have had recent bereavement and other stressful conditions were excluded from the study. Patients who were taking medicine (e.g., a drug of abuse or a medication) that can cause depression, and patients who had recent bereavement were also excluded.

Face-to-face interview could be conducted of 1,114 eligible consenting subjects by using a semi-structured questionnaire containing sociodemographic parameters and relevant information about depression and diabetes. Biochemical test results and treatmentrelated information were taken from patients' records. The Hospital Anxiety and Depression Scale (HAD) [29] was used to screen all patients for psychiatric manifestation. The beauty of the HADS score is its simplicity, speed, and ease of use. Very few (literate) people have difficulty completing it, on paper or electronically. It assesses both anxiety and depression, which commonly coexist [56]. Anxiety is poorly recognized by clinicians, so should be actively sought [57]. Anxiety often precedes depression in response to stressors and identifying the employee with high or rising anxiety before depression allows occupational health practitioners to advise on early intervention measures, while the employee is still at work and potentially avoid sickness absence. This would be missed using a depression only questionnaire such as the Patient Health Questionnaire (PHQ9). HADS focuses on nonphysical symptoms so that it can be used to diagnose depression in people with significant physical ill-health. Any overlap, for instance, impaired concentration secondary to pain rather than depression and is usually easy to separate on an individual basis. HADS does not include all of the diagnostic criteria of depression (Diagnostic and Statistical Manual of Mental Disorders, Fourth/Fifth Edition [DSM IV/V]) or all those required by the Health and Work Development Unit National Depression and Long-Term Sickness Absence Screening Audit [58].

Those diagnosed by HADS were subsequently reassessed using structured clinical interview for DSM-5 Disorders - Clinician Version (SCID-5-CV) [59]. Specialist psychiatrist was employed for the administration of HADS and SCID-5-CV for the assessment of depression. Informed written consent was obtained from each of the patients. Patients with clinically significant psychiatric illness were referred to relevant department for treatment. Ethical approval was obtained from institutional review board.

HADS and SCID-5-CV questionnaire data were analyzed through assigning score prescribed by the instrument. Diagnosis of depression was confirmed based on defined cutoff score (HADS $\geq 8$ ). T2DM diagnosed at age $<40$ years were considered as early onset T2DM $[60,61]$. Descriptive statistics were generated to compare the demography and other clinical criteria among early onset and late-onset T2DM patients. Univariate association of depression with factors including sociodemographic, anthropometry, time of onset and duration of diabetes, treatment regiments of diabetes, poor glycemic control $(\mathrm{HbAlc}>6.5)$, comorbidity, and diabetic complication status were assessed using binary logistic regression. Subsequently, association between age of onset category ( $<40$ and $\geq 40$ years) and risk of depression was asses through multivariable mixed-effect logistic regression adjusting for random variation in the area of residence and plausible confounders. Stat $16 / \mathrm{SE}^{\circledR}$ was used for statistical analysis. 
Table 1. Descriptive statistics of study participants by categories of onset of diabetes

\begin{tabular}{|c|c|c|c|c|}
\hline \multirow[t]{2}{*}{ Variables } & \multicolumn{2}{|c|}{ Onset of diabetes } & \multirow[t]{2}{*}{ Total } & \multirow[t]{2}{*}{$p$ value } \\
\hline & $\geq 40$ years & $<40$ years & & \\
\hline \multicolumn{5}{|l|}{ Age } \\
\hline$<50$ years & $221(29.4)$ & $286(79.0)$ & $507(45.5)$ & \multirow{3}{*}{$<0.001$} \\
\hline 50-59 years & $305(40.6)$ & $63(17.4)$ & $368(33.0)$ & \\
\hline$\geq 60$ years & $226(30.0)$ & $13(03.6)$ & $239(21.5)$ & \\
\hline \multicolumn{5}{|l|}{ Gender } \\
\hline Male & $230(30.6)$ & $64(17.7)$ & $294(26.4)$ & \multirow{2}{*}{$<0.001$} \\
\hline Female & $522(69.4)$ & $298(82.3)$ & $820(73.6)$ & \\
\hline \multicolumn{5}{|l|}{ Highest education attainment } \\
\hline Primary or below & $393(52.3)$ & $166(45.9)$ & $559(50.2)$ & \multirow{3}{*}{0.130} \\
\hline Secondary & $213(28.3)$ & $114(31.5)$ & $327(29.4)$ & \\
\hline Above secondary & $146(19.4)$ & $82(22.7)$ & $228(20.5)$ & \\
\hline \multicolumn{5}{|l|}{ Income, tk/month } \\
\hline$<10,000$ & $338(45.0)$ & $178(49.2)$ & $516(46.3)$ & \multirow{3}{*}{0.398} \\
\hline $10,000-20,000$ & $217(28.9)$ & $94(26.0)$ & $311(27.9)$ & \\
\hline$>20,000$ & $197(26.0)$ & $90(24.9)$ & $287(25.8)$ & \\
\hline \multicolumn{5}{|l|}{ Place of residence } \\
\hline Rural & $214(28.5)$ & $88(24.3)$ & $302(27.1)$ & \multirow{2}{*}{0.145} \\
\hline Urban & $538(71.5)$ & $274(75.5)$ & $812(72.9)$ & \\
\hline \multicolumn{5}{|l|}{ Spouse status } \\
\hline Lives with spouse & $557(74.1)$ & $304(84.0)$ & $861(77.3)$ & \multirow{2}{*}{$<0.001$} \\
\hline Lives without spouse & $195(25.9)$ & $58(16.0)$ & $253(22.7)$ & \\
\hline \multicolumn{5}{|l|}{ Family history of diabetes } \\
\hline No & $244(32.5)$ & $90(24.9)$ & $334(30.0)$ & \multirow{2}{*}{$<0.001$} \\
\hline Yes & $508(67.5)$ & $272(75.1)$ & $780(70.0)$ & \\
\hline \multicolumn{5}{|l|}{$\mathrm{BMI}$} \\
\hline Normal & $365(48.5)$ & $191(52.8)$ & $556(49.9)$ & \\
\hline Overweight & $371(49.3)$ & $158(43.6)$ & $529(47.5)$ & 0.103 \\
\hline Underweight & $16(2.1)$ & $13(3.6)$ & $29(2.6)$ & \\
\hline Duration of diabetes & & & & \\
\hline$<5$ years & $340(45.2)$ & $81(22.4)$ & $421(37.8)$ & \\
\hline 5-10 years & $225(29.9)$ & $109(30.1)$ & $334(30.0)$ & \\
\hline $10-15$ years & $124(16.5)$ & $115(31.8)$ & $239(21.5)$ & $<0.001$ \\
\hline$\geq 15$ years & $63(8.4)$ & $57(15.7)$ & $120(10.8)$ & \\
\hline $\mathrm{HbAlc}$ & & & & \\
\hline $\mathrm{HbA} 1 \mathrm{c} \leq 6.5$ & $359(47.7)$ & $160(44.2)$ & $519(46.6)$ & \\
\hline $\mathrm{HbAlc}>6.5$ & $393(52.3)$ & $202(55.8)$ & $595(53.4)$ & 0.267 \\
\hline Comorbidity & & & & \\
\hline None & $164(21.8)$ & $90(24.9)$ & $254(22.8)$ & \\
\hline One or more & $588(78.2)$ & $272(75.1)$ & $860(77.2)$ & 0.255 \\
\hline Diabetic complication & & & & \\
\hline None & $462(61.4)$ & $183(50.5)$ & $645(57.9)$ & \\
\hline One or more & $290(38.6)$ & $179(49.5)$ & $469(42.1)$ & 0.001 \\
\hline Starting treatment & & & & \\
\hline Medical nutrition therapy & $154(20.5)$ & $57(15.7)$ & $211(18.9)$ & \\
\hline Oral hypoglycemic agents & $437(58.1)$ & $202(55.8)$ & $639(57.4)$ & 0.016 \\
\hline Insulin alone/combination & $161(21.4)$ & $103(28.5)$ & $264(23.7)$ & \\
\hline Current treatment regimen & & & & \\
\hline Medical nutrition therapy & $60(7.98)$ & $36(9.9)$ & $96(8.6)$ & \\
\hline Oral hypoglycemic agents & $406(54.0)$ & $143(39.5)$ & $549(49.3)$ & $<0.001$ \\
\hline Insulin alone/combination & $286(38.0)$ & $183(50.6)$ & $469(23.7)$ & \\
\hline Depression & & & & \\
\hline No & $447(59.4)$ & $175(48.3)$ & $622(55.8)$ & \\
\hline Yes & $305(40.6)$ & $187(51.7)$ & $492(44.2)$ & $<0.001$ \\
\hline
\end{tabular}


Table 2. Univariate association between depression and background characteristics

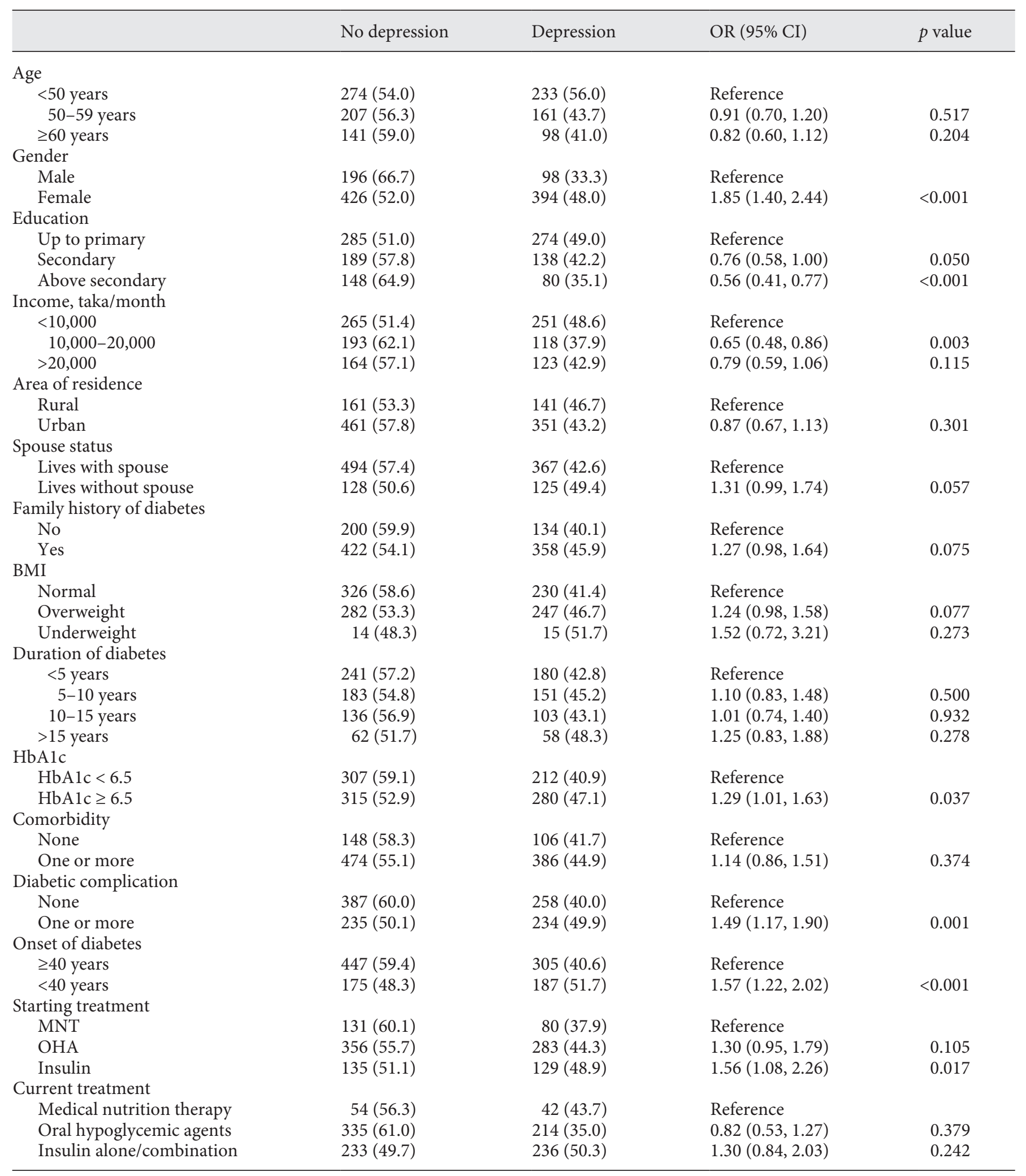




\section{Results}

In total $1,114, \mathrm{~T} 2 \mathrm{DM}$ patients had been recruited in the study. Of them, $45.5 \%$ were aged $<50$ years, $33.0 \%$ aged between 55 and 59 years, and around $21.5 \%$ were aged 60 years and above. Majority (73.6\%) of the patients were female, urban, or semi-urban residents (75.5\%) and lives with spouse (77.3\%). Around $49.8 \%$ had attended or completed primary level education, $47.5 \%$ are overweight. More than three-fourths of the participants (77.2\%) presented with 1 or more comorbidities. Among the comorbidities hypertension (53.2\%), dyslipidemia (44.9\%), osteoarthritis (16.4\%), and ischemic heart disease (10.7\%) are notable. Less than one-third of the respondents $(32.5 \%)$ had the diagnosed with T2DM before the age of 40 years and $70.0 \%$ presented with history of diabetes among family members. Median duration of diabetes among participants was 6 years (Interquartile range 3-10 years), $53.4 \%$ had $\mathrm{HbA1c}>6.5$. Upon diagnosis of DM, $57.4 \%$ started with oral antihyperglycemic drug (OAD) treatment and $23.7 \%$ with insulin. During the period of the study, $49.3 \%$ were on OADs, and $42.1 \%$ were receiving insulin alone or with OAD. Around $42.1 \%$ of the participants presented with 1 or more complications related to diabetes or its treatment. Most reported complications were diabetic neuropathy $(30.1 \%)$, diabetic retinopathy (12.9\%), diabetic nephropathy (5.5\%), and cataract (5.7\%). Based on detailed psychological assessment, $44.2 \%$ were found to have depression.

Table 1 facilitates comparison of demography and diabetes characteristics between 2 groups T2DM patients: early and late onset. Female preponderance was found in early onset T2DM patients $(p<0.01)$, younger $(p<0.01)$, live with a spouse $(p<0.01)$, with a positive family history of DM $(p<0.01)$ and have longer duration of diabetes $(p<0.01)$. Patients with early onset T2DM were more likely to present with 1 or more diabetic complications $(p<0.01)$ as well, received insulin treatment $(p 0.00)$, and had depression $(p<0.01)$.

Table 2 depicts the association of patient characteristics with depression derived from univariate analysis. Female gender $(p<0.001)$, poor glycemic control $(p=$ $0.037)$, presence of diabetic complication $(p=0.001)$, insulin as a starting treatment $(p=0.017)$, and earlier onset of diabetes $(p<0.001)$ have been related to greater risk of depression. Higher educational attainment $(p<0.001)$ was found to be protective of depression.

Table 3 presents the predictors of depression adjusting for plausible confounders as well as geographical variation of residence through multivariable mixed-ef-
Table 3. Multivariate analysis for predictors of depression among T2DM

\begin{tabular}{|c|c|c|}
\hline & OR $(95 \% \mathrm{CI}) *$ & $p$ value \\
\hline \multicolumn{3}{|l|}{ Gender } \\
\hline Male & Reference & \\
\hline Female & $1.42(1.03,1.98)$ & 0.033 \\
\hline \multicolumn{3}{|l|}{ Education level } \\
\hline Primary & Reference & \\
\hline Secondary & $0.85(0.63,1.18)$ & 0.297 \\
\hline Higher secondary & $0.69(0.43,1.08)$ & 0.066 \\
\hline \multicolumn{3}{|l|}{ Income, tk/month } \\
\hline$<10,000$ & Reference & \\
\hline $10,000-20,000$ & $0.80(0.53,1.08)$ & 0.172 \\
\hline$>20,000$ & $1.05(0.73,1.48)$ & 0.744 \\
\hline \multicolumn{3}{|l|}{ Spouse status } \\
\hline Lives with spouse & Reference & \\
\hline Lives without spouse & $1.10(0.83,1.58)$ & 0.554 \\
\hline \multicolumn{3}{|l|}{ Family history of diabetes } \\
\hline No & Reference & \\
\hline Yes & $1.33(1.03,1.78)$ & 0.038 \\
\hline \multicolumn{3}{|l|}{ Duration of diabetes } \\
\hline$<5$ years & Reference & \\
\hline 5-10 years & $0.80(0.53,1.28)$ & 0.308 \\
\hline $10-15$ years & $0.90(0.53,1.58)$ & 0.722 \\
\hline$\geq 15$ years & $0.62(0.13,2.58)$ & 0.512 \\
\hline \multicolumn{3}{|l|}{$\mathrm{HbAlc}$} \\
\hline HbA1c $<6.5$ & Reference & \\
\hline $\mathrm{HbA} 1 \mathrm{c} \geq 6.5$ & $1.31(1.03,1.68)$ & 0.028 \\
\hline \multicolumn{3}{|l|}{ Diabetic complication } \\
\hline No & Reference & \\
\hline Yes & $1.37(1.03,1.78)$ & 0.017 \\
\hline \multicolumn{3}{|l|}{ Onset of diabetes } \\
\hline$\geq 40$ years & Reference & \\
\hline$<40$ years & $1.57(1.13,2.28)$ & 0.011 \\
\hline \multicolumn{3}{|l|}{ Initial treatment modality } \\
\hline Medical nutrition therapy & Reference & \\
\hline Oral hypoglycemic agents & $0.99(0.87,1.94)$ & 0.60 \\
\hline Insulin alone/combination & $1.97(0.134,2.18)$ & 0.04 \\
\hline \multicolumn{3}{|l|}{ Current treatment modality } \\
\hline Medical nutrition therapy & Reference & \\
\hline Oral hypoglycemic agents & $0.90(0.53,1.48)$ & 0.670 \\
\hline Insulin alone/combination & $1.34(0.83,2.18)$ & 0.209 \\
\hline
\end{tabular}

T2DM, type 2 diabetes mellitus. * Odds ratios and 95\% CI were generated using mixed-effect logistic regression.

fect logistic regression. Early onset T2DM patient had about 57\% higher risk of depression (OR 1.57; 95\% CI $1.13-2.28$; $p=0.011$ ) in comparison to those with nonearly onset T2DM. Among other factors, a positive family history for diabetes (OR 1.33; 95\% CI 1.03-1.78; $p=$ 0.038 ), poor glycemic control (OR 1.31 ; $95 \%$ CI $1.03-$ $1.68 ; p=0.028)$, presence of 1 , or more diabetic complications (OR 1.37; 95\% CI 1.03-1.78; $p=0.011$ ) also had
60

Dubai Diabetes Endocrinol J 2021;27:55-65 DOI: $10.1159 / 000515683$
Riaz/Selim/Neo/Karim/Zaman 
increased risk of depression. The patients' initial modality of treatment has impacts on depression with higher likelihood among insulin users $(1.97[0.134,2.18 ; p=$ 0.04 ], $p=0.60$ ) than OAD users (OR 0.99; 95\% CI 0.87, $1.94, p=0.60)$.

\section{Discussion/Conclusion}

Our finding confirms that the early onset T2DM patients had greater risk of developing depression adjusting for all plausible confounders in comparison to patients without early onset T2DM. Among other factors, a positive family history for diabetes, poor glycemic control, and presence of 1 or more diabetic complications also showed increased risk of depression among patients with T2DM. Our finding has significant clinical implication because of the potential of affecting risk status of the subjects and also of management.

Almost all patients with DM may suffer from one or other chronic complications of it and that is kept in consideration while treating them $[1,32]$. Several observational studies supported this hypothesis [33]. Like most chronic diseases, diabetes spawns stress and anxiety among patients and is likely to a generate breeds of negative emotions such as frustration, fear, sadness, guilt, and also anger to some extent as they accept the limitations imposed by being stripped as diabetes. The perception of being destitute is further deepened among them as they anticipate a major shift to a new lifestyle and failure to foresee a cure [34] and perception about worsening health [35]. Many of these psychological events alone or in orchestra may culminate into subclinical and eventually to clinical depression $[16,59]$. Exposure to such a battery of emotional events earlier in life may increase the risk of depression even further.

The patients with diabetes with higher BMI suffered from depression more ( $p$ 0.007). Svenningsson et al. [57] suggested an association between depression and obesity in patients with DM type 2 in both genders [60]. Recently, a report showed that there is a positive association between having a high BMI and the risk to develop T2DM [61]. In general, literature shows evidence that depression is associated with metabolic disorders in patients with T2DM [62]. Furthermore, it has been suggested that the presence of metabolic alterations in patients with diabetes type 2 such as obesity, could increase the severity of depression $[63,64]$. The distinct mechanisms that link obesity to insulin resistance and DM type 2 are related to an increased production of adipokines and more adipose tis-

Depression in Early Onset Type 2

Diabetes sue as a result $[65,66]$; these molecules are involved in many clinical manifestations of DM type 2, and they are also associated with arterial hypertension and cardiovascular disease [67]. First, the adipose tissue of the obese patient becomes resistant to the action of insulin due to the effect of some of these adipokines; for instance, the tumoral necrosis factor alpha (TNF- $\alpha$ ) and interleukine- 6 (IL-6) [68]. Second, this resistance occurs in other tissues; therefore, insulin and glucose levels increase. This increase, along with high adipokines levels (that occur in DM type 2), leads to different adverse events, such as endothelial dysfunction [69], increase in oxidative stress [70], impairments in lipoprotein metabolism, and increase in blood pressure [70]. [71, 98]

Early onset T2DM patients have an enhanced risk of the earlier development of cardiovascular (microvascular and macrovascular) complications as well as psychological morbidity during course of their life [71]. They are likely to represent a metabolic and genetically heterogeneous group, exhibiting more aggressive form of the disease, require insulin treatment sooner to attain good glycemic control, and suffer from severe chronic complications as a whole $[72,73]$.

The socioeconomic and biological implications of having T2DM at an earlier age are believed to be colossal. The usual findings of higher frequencies of complication at an earlier stage for this subgroup indicate that these patients with T2DM are more likely to experience increased distress, in both magnitude and intensity in comparison to the later onset cohort at similar chronological age, which may spawn depressive illness. Patients with T2DM who had been diagnosed at a younger age are likely to possess higher likelihood for occurrence of diabetic complications and are associated with premature death at a younger age than those who had been diagnosed later.

In this subgroup, increased risk of depression in later life may be imparted by the longer duration of diabetes. They incur longer lifetime exposure to the hyperglycemic ambiance, accumulate more emotional burden and possess greater risk of various worsening complications including depression [74-76]. In early onset T2DM, patients are somehow less likely to comply with the required regulation and restriction attributable partly to rebellious nature of being young may result in poorer glycemic control as measured by blood HbAlc concentration. High concentrations of $\mathrm{HbA} 1 \mathrm{c}$ have already been indicted as a predictor depression in T2DM [77].

If the management of diabetes is taken in context, surprisingly patients with untreated diabetes were reported 
to exert less likelihood of depression than patients with treated diabetes [15]. Possible explanation of such finding may lie in the complexity, discomfort, and burden posed by the treatment and limitation posed by the management process, particularly at such a younger age. The issue warrants further detailed research.

$\mathrm{DM}$ is a very important noncommunicable, chronic disease which is one of the major causes of death, requiring higher management cost and still is notorious to shorten the life span of the patients [6]. The failure of understanding the association or relationship of pathophysiology and exact nature of co-occurrence threatened the proper management of physiological components in DM and expected outcomes could not be achieved. A compelling reason for putting emphasis in the detection of depression in diabetes is its propensity to suicide. Besides, diabetes distress has been found to have impact on self-care behaviors, glycemic control, and quality of life [78]. It is crucial to develop screening and intervention strategies to help these early onset T2DM patients to cope with psychological pressure in the early stage when caring for patients with diabetes. Further co-existence of diabetes and depression by itself is likely to expedite the progress the disease resulting in earlier development of complications. Management of risk factors for diabetes complications is likely to be inadequate among early onset subjects [79-81]. Adequate and sensible measure needs to be devised to address the treatment gap in this subgroup.

History of depression, current depression, and antidepressant medication use are risk factors for the development of type 2 diabetes, especially if the individual has other risk factors such as obesity and family history of type 2 diabetes [82-88]. Elevated depressive symptoms and depressive disorders affect 1 in 4 patients with type 1 or type 2 diabetes $[89,90]$. Thus, routine screening for depressive symptoms is indicated in this high-risk population including people with type 1 or type 2 diabetes, gestational DM, and postpartum diabetes. Regardless of diabetes type, women have significantly higher rates of depression than men [91-94]. Thus, American Diabetes Association recommends to consider annual screening of all patients with diabetes, especially those with a selfreported history of depression, for depressive symptoms with age-appropriate depression screening measures, recognizing that further evaluation will be necessary for individuals who have a positive screen and if needed refer for treatment of depression should be made to mental health providers with experience using cognitive-behavioral therapy, interpersonal therapy, or other evidence- based treatment approaches in conjunction with collaborative care with the patient's diabetes treatment team [95]. The initiation of drugs for diabetes found to have impact on depression with higher likelihood among insulin users $(1.97[0.134,2.18 ; p=0.04], p=0.60)$ than OAD users (OR 0.99; 95\% CI 0.87, 1.94, $p=0.60$ ). Bai et al. [96] described a higher frequency of depression among T2DM patients who received treatment with insulin.

The study suffers from 1 limitation by using the selfreported depressive symptoms information as self-reported symptoms of depression are more likely to have been influenced by subjective emotional and distress related rather than specific depressive disorders. The measure of depression was based on HADS score and SCID$5-\mathrm{CV}$; however, specialist psychiatrists were employed to assess the depression although substantial intra-observer variation using a particular scale or format to evaluate depression. Despite the abovementioned limitations, findings of the study would contribute in deepening the relationship of diabetes and depression and vice versa.

In conclusion, significant risks are found among patients with early onset T2DM to develop depression. The young adults with T2DM should be screened to detect depression to optimization of medical care aiming prevention or reduction of the onset of complications. Future prospective observation studies may design to ascertain the etiopathogenesis of depression in early onset diabetes along with other cardiometabolic complications and to facilitate effective choice of management to halt or prevent the morbidity and mortality.

\section{Acknowledgement}

The authors are grateful to all the T2DM patients who participated in the study and the psychiatrist who work relentlessly to complete the data collection. The study received research grant from WHO country office Bangladesh. WHO, however, had no role in the study design, data collection, and interpretation.

\section{Statement of Ethics}

The study obtained ethical approval from Ethical Review Committee of Bangladesh Medical Research Council. The number of ERC 1173 dated- April 17, 2019.
Riaz/Selim/Neo/Karim/Zaman 


\section{Conflict of Interest Statement}

The authors have no conflicts of interest to declare.

\section{Funding Sources}

The study received research grant from WHO, Bangladesh.

\section{Author Contributions}

M.N.K., M.M.Z., S.S., and B.K.R. conceptualized the research. M.M.Z., S.S., and B.K.R. oversaw the study logistics and data collection. M.M.Z. conducted quality control. M.N.K. performed statistical analysis of the data. M.N.K. and M.N. drafted the manuscript. M.M.Z., S.S., and B.K.R. reviewed the manuscript and provided critical input. All the authors read and approved final manuscript.

\section{References}

1 Egede LE, Zheng D, Simpson K. Comorbid depression is associated with increased health care use and expenditures in individuals with diabetes. Diabetes Care. 2002;25(3):464-70.

2 Centers for Disease Control and Prevention (CDC). Serious psychological distress among persons with diabetes: New York city. Morb Mortal Wkly Rep. 2003;2004(53):1089-92.

3 Anderson RJ, Freedland KE, Clouse RE, Lustman PJ. The prevalence of comorbid depression in adults with diabetes: a meta-analysis. Diabetes Care. 2001;24(6):1069-78.

4 Zhao W, Chen Y, Lin M, Sigal RJ. Association between diabetes and depression: sex and age differences. Public Health. 2006;120(8):696704.

5 Eaton WW. Epidemiologic evidence on the comorbidity of depression and diabetes. J Psychosom Res. 2002;53(4):903-6.

6 Ciechanowski PS, Katon WJ, Russo JE. Depression and diabetes: impact of depressive symptoms on adherence, function, and costs. Arch Intern Med. 2000;160(21):3278-85.

7 Moussavi S, Chatterji S, Verdes E, Tandon A, Patel V, Ustun B. Depression, chronic diseases, and decrements in health: results from the world health surveys. Lancet. 2007;370(9590): 851-8.

8 Das R, Singh O, Thakurta RG, Khandakar MR, Ali SN, Mallick AK, et al. Prevalence of depression in patients with type II diabetes mellitus and its impact on quality of life. Indian J Psychol Med. 2013;35(3):284-9.

9 Riba M. Depression and diabetes. J Nerv Ment Dis. 2011;199(11):907.2.

10 Egede LE, Ellis C. Diabetes and depression global perspectives. Diabetes Res Clin Pract. 2010;87(3):302-12.

11 Breznoščáková D, Nagyova I. Depression and glucose metabolism (diabetes mellitus). In: Kocabasoglu N, editor. Mental and behavioural disorders and diseases of the nervous system. Mood disorders. Rijeka (Croatia): InTechOpen; 2013.

12 Rustad JK, Musselman DL, Nemeroff CB. The relationship of depression and diabetes: pathophysiological and treatment implications. Psychoneuroendocrinology. 2011;36(9):1276-86.

13 Leone T, Coast E, Narayanan S, de Graft Aikins A. Diabetes and depression comorbidity and socio-economic status in low and middle income countries (LMICs): a mapping of the evidence. Global Health. 2012;8:39.
14 Talbot F, Nouwen A. A review of the relationship between depression and diabetes in adults: is there a link? Diabetes Care. 2000; 23(10): 1556-62.

15 Engum A. The role of depression and anxiety in onset of diabetes in a large population-based study. J Psychosom Res. 2007;62(1):31-8.

16 Palinkas LA, Lee PP, Barrett-Connor E. A prospective study of type 2 diabetes and depressive symptoms in the elderly: the Rancho Bernardo Study. Diabet Med. 2004;21(11): 1185-91.

17 Kivimaki M, Tabak AG, Batty GD, Singh-Manoux A, Jokela M, Akbaraly TN, et al. Hyperglycemia, type 2 diabetes, and depressive symptoms: the British Whitehall II study. Diabetes Care. 2009;32(10):1867-9.

18 Mezuk B, Eaton WW, Albrecht S, Golden SH. Depression and type 2 diabetes over the lifespan: a meta-analysis. Diabetes Care. 2008; 31(12):2383-90.

19 Moulton CD, Pickup JC, Ismail K. The link between depression and diabetes: the search for shared mechanisms. Lancet Diabetes Endocrinol. 2015;3(6):461-71.

20 Golden SH, Lazo M, Carnethon M, Bertoni AG, Schreiner PJ, Diez Roux AV, et al. Examining a bidirectional association between depressive symptoms and diabetes. JAMA. 2008;299(23):2751-9.

21 Silva N, Atlantis E, Ismail K. A review of the association between depression and insulin resistance: pitfalls of secondary analyses or a promising new approach to prevention of type 2 diabetes? Curr Psychiatry Rep. 2012; 14(1):8-14.

22 Kessler RC, Amminger GP, Aguilar-Gaxiola S, Alonso J, Lee S, Ustün TB. Age of onset of mental disorders: a review of recent literature. Curr Opin Psychiatry. 2007;20(4):359-64

23 Scherrer JF, Xian H, Lustman PJ, Franz CE, McCaffery J, Lyons MJ, et al. A test for common genetic and environmental vulnerability to depression and diabetes. Twin Res Hum Genet. 2011;14(2):169-72.

24 Samaan Z, Garasia S, Gerstein HC, Engert JC, Mohan V, Diaz R, et al. Lack of association between type 2 diabetes and major depression: epidemiologic and genetic evidence in a multiethnic population. Transl Psychiatry. 2015;5:e618.

25 Agardh E, Allebeck P, Hallqvist J, Moradi T, Sidorchuk A. Type 2 diabetes incidence and socio-economic position: a systematic review and meta-analysis. Int J Epidemiol. 2011; 40(3):804-18.

26 Folb N, Lund C, Fairall LR, Timmerman V, Levitt NS, Steyn K, et al. Socioeconomic predictors and consequences of depression among primary care attenders with non-communicable diseases in the Western Cape, South Africa: cohort study within a randomised trial. BMC Public Health. 2015;15: 1194.

27 Kyrou I, Tsigos C. Stress hormones: physiological stress and regulation of metabolism. Curr Opin Pharmacol. 2009;9(6):787-93.

28 Chrousos GP. Stress and disorders of the stress system. Nat Rev Endocrinol. 2009;5(7): 374-81.

29 Herbert J, Goodyer IM, Grossman AB, Hastings MH, de Kloet ER, Lightman SL, et al. Do corticosteroids damage the brain? J Neuroendocrinol. 2006;18(6):393-411.

30 Moulton CD, Costafreda SG, Horton P, Ismail K, Fu CH. Meta-analyses of structural regional cerebral effects in type 1 and type 2 diabetes. Brain Imaging Behav. 2015;9(4): 651-62.

31 Sumlin LL, Garcia TJ, Brown SA, Winter MA, García AA, Brown A, et al. Depression and adherence to lifestyle changes in type 2 diabetes: a systematic review. Diabetes Educ. 2014; 40(6):731-44.

32 Zeman M, Jirák R, Zák A, Jáchymová M, Vecka M, Tvrzická E, et al. [Metabolic syndrome and depression: clinical relations]. Cas Lek Cesk. 2008;147(2):75-80.

33 Stankovic Z, Jasovic-Gasic M, Lecic-Tosevski D. Psychological problems in patients with type 2 diabetes: clinical considerations. Vojnosanit Pregl. 2013;70(12):1138-44.

34 Degmecic D, Bacun T, Kovac V, Mioc J, Horvat J, Vcev A. Depression, anxiety and cognitive dysfunction in patients with type 2 diabetes mellitus: a study of adult patients with type 2 diabetes mellitus in Osijek, Croatia. Coll Antropol. 2014;38(2):711-6.

35 Egede LE, Zheng D, Simpson K. Comorbid depression is associated with increased health care use and expenditures in individuals with diabetes. Diabetes Care. 2002;25(3):464-70.

36 Mello AF, Mello MF, Carpenter LL, Price LH. Update on stress and depression: the role of the hypothalamic-pituitary-adrenal (HPA) axis. Rev Bras Psiquiatr. 2003;25(4):231-8. 
37 Nestler EJ, Barrot M, DiLeone RJ, Eisch AJ, Gold SJ, Monteggia LM. Neurobiology of depression. Neuron. 2002;34(1):13-25.

38 Groves JO. Is it time to reassess the BDNF hypothesis of depression? Mol Psychiatry. 2007; 12(12):1079-88.

39 Castillo-Quan JI, Barrera-Buenfil DJ, PérezOsorio JM, Alvarez-Cervera FJ. [Depression and diabetes: from epidemiology to neurobiology]. Rev Neurol. 2010;51(6):347-59.

40 Koo J, Yue P, Gal AA, Khuri FR, Sun SY. Maintaining glycogen synthase kinase- 3 activity is critical for mTOR kinase inhibitors to inhibit cancer cell growth. Cancer Res. 2014; 74(9):2555-68.

41 Qu ZS, Li L, Sun XJ, Zhao YW, Zhang J, Geng $Z$, et al. Glycogen synthase kinase-3 regulates production of amyloid- $\beta$ peptides and tau phosphorylation in diabetic rat brain. ScientificWorldJournal. 2014;2014:878123.

42 Ronai Z, Kovacs-Nagy R, Szantai E, Elek Z, Sasvari-Szekely M, Faludi G, et al. Glycogen synthase kinase 3 beta gene structural variants as possible risk factors of bipolar depression. Am J Med Genet B Neuropsychiatr Genet. 2014; 165B(3):217-22.

43 Jope RS. Glycogen synthase kinase- 3 in the etiology and treatment of mood disorders. Front Mol Neurosci. 2011;4:16.

44 Blazer DG, Moody-Ayers S, Craft-Morgan J, Burchett B. Depression in diabetes and obesity: racial/ethnic/gender issues in older adults. J Psychosom Res. 2002;53(4):913-6.

45 Everson SA, Maty SC, Lynch JW, Kaplan GA. Epidemiologic evidence for the relation between socioeconomic status and depression, obesity, and diabetes. J Psychosom Res. 2002; 53(4):891-5.

46 Moulton CD, Pickup JC, Ismail K. The link between depression and diabetes: The search for shared mechanisms. Lancet Diabetes Endocrinol. 2015;3(6):461-71. Available online: http:/10.1016/S2213-8587(15)00134-5.

47 Labad J, Price JF, Strachan MW, Fowkes FG, Ding J, Deary IJ, et al. Symptoms of depression but not anxiety are associated with central obesity and cardiovascular disease in people with type 2 diabetes: the Edinburgh Type 2 Diabetes Study. Diabetologia. 2010;53(3): 467-71.

48 Sacco WP, Wells KJ, Vaughan CA, Friedman A, Perez S, Matthew R. Depression in adults with type 2 diabetes: the role of adherence, body mass index, and self-efficacy. Health Psychol. 2005;24(6):630-4.

49 Julia C, Czernichow S, Charnaux N, Ahluwalia N, Andreeva V, Touvier M, et al. Relationships between adipokines, biomarkers of endothelial function and inflammation and risk of type 2 diabetes. Diabetes Res Clin Pract. 2014;105(2):231-8.

50 de Luis DA, Aller R, Izaola O, Gonzalez Sagrado M, Conde R, de la Fuente B. Role of insulin resistance and adipocytokines on serum alanine aminotransferase in obese patients with type 2 diabetes mellitus. Eur Rev Med Pharmacol Sci. 2013;17(15):2059-64.
51 Ziegler D. Type 2 diabetes as an inflammatory cardiovascular disorder. Curr Mol Med. 2005; 5(3):309-22.

52 Pereira FO, Frode TS, Medeiros YS. Evaluation of tumour necrosis factor alpha, interleukin-2 soluble receptor, nitric oxide metabolites, and lipids as inflammatory markers in type 2 diabetes mellitus. Mediators Inflamm. 2006;2006(1):39062.

53 Bachmayer C, Kemmer A, Ehrmann N, Hasenberg T, Lammert A, Hammes H-P. Adipokines and endothelial dysfunction in obesity WHO III. Microvasc Res. 2013;89:12933.

54 Crujeiras AB, Díaz-Lagares A, Carreira MC, Amil M, Casanueva FF. Oxidative stress associated to dysfunctional adipose tissue: a potential link between obesity, type 2 diabetes mellitus and breast cancer. Free Radic Res. 2013;47(4):243-56.

55 Adler AI, Stratton IM, Neil HA, Yudkin JS, Matthews DR, Cull CA, et al. Association of systolic blood pressure with macrovascular and microvascular complications of type 2 diabetes (UKPDS 36): prospective observational study. BMJ. 2000;321(7258):412-9.

56 Antuna-Puente B, Feve B, Fellahi S, Bastard JP. Adipokines: the missing link between insulin resistance and obesity. Diabetes Metab. 2008;34(1):2-11.

57 Svenningsson I, Björkelund C, Marklund B, Gedda B. Anxiety and depression in obese and normal-weight individuals with diabetes type 2: a gender perspective. Scand J Caring Sci. 2012;26(2):349-54.

58 Ganz ML, Wintfeld N, Li Q, Alas V, Langer J, Hammer M, et al. The association of body mass index with the risk of type 2 diabetes: a case-control study nested in an electronic health records system in the United States. Diabetol Metab Syndr. 2014;6(1):50.

59 Katon WJ, Russo JE, Heckbert SR, Lin EH, Ciechanowski P, Ludman E, et al. The relationship between changes in depression symptoms and changes in health risk behaviors in patients with diabetes. Int J Geriatr Psychiatry. 2010;25(5):466-75.

60 Nouwen A, Nefs G, Caramlau I, Connock M, Winkley K, Lloyd CE, et al. Prevalence of depression in individuals with impaired glucose metabolism or undiagnosed diabetes: a systematic review and meta-analysis of the European depression in diabetes (EDID) research consortium. Diabetes Care. 2011;34(3):752-62.

61 Dabelea D, DeGroat J, Sorrelman C, Glass M, Percy CA, Avery C, et al. Diabetes in Navajo youth: prevalence, incidence, and clinical characteristics: the SEARCH for Diabetes in Youth Study. Diabetes Care. 2009;32(Suppl 2):S141-7.

62 Sharp P, Brown B, Qureshi A. Age at diagnosis of diabetes in a secondary care population: 1992-2005. Br J Diabetes Vasc Dis. 2008;8: 92-5.

63 Drake AJ, Smith A, Betts PR, Crowne EC, Shield JP. Type 2 diabetes in obese white children. Arch Dis Child. 2002;86(3):207-8.
64 National Institute for Health and Clinical Excellence. Type 2 diabetes. The management of type 2 diabetes. NICE clinical guideline. London: NICE; 2008.

65 Hillier TA, Pedula KL. Characteristics of an adult population with newly diagnosed type 2 diabetes: the relation of obesity and age of onset. Diabetes Care. 2001;24(9):1522-7.

66 Hillier TA, Pedula KL. Complications in young adults with early-onset type 2 diabetes: losing the relative protection of youth. Diabetes Care. 2003;26(11):2999-3005.

67 Hatunic M, Burns N, Finucane F, Mannion C, Nolan JJ. Contrasting clinical and cardiovascular risk status between early and later onset type 2 diabetes. Diab Vasc Dis Res. 2005;2(2): $73-5$.

68 Song S, Hardisty C. Cardiovascular risk profile of early and later onset type 2 diabetes. Pract Diab Int. 2007;24(1):20-4.

69 British Cardiac Society, British Hypertension Society, Diabetes UK, Heart UK, Primary Care Cardiovascular Society, Stroke Society. JBS 2: joint British societies' guidelines on prevention of cardiovascular disease in clinical practice. Heart. 2005;91(Suppl V):v1-52.

70 Wilmot EG, Leggate M, Khan JN, Yates T, Gorely T, Bodicoat DH, et al. Type 2 diabetes mellitus and obesity in young adults: the extreme phenotype with early cardiovascular dysfunction. Diabet Med. 2014;31(7):794-8.

71 McManus S, Meltzer H, Brugha T, Bebbington P, Jenkins R. Adult psychiatric morbidity in england 2007. Results of household survey. Available from: http://www.hscic.gov.uk/catalogue/PUB02931/adul-psyc-morb-res-housur-eng-2007-rep.pdf. Accessed 2019 Feb.

72 National Collaborating Centre for Mental Health. Common mental health disorders: the NICE guideline on identification and pathways to care. National Clinical Guideline Number 123. Available from: http://www.nice. org.uk/nicemedia/live/13476/54604/54604. pdf. Accessed 2019 Feb.

73 Occupational Health Clinical Effectiveness Unit Audit Development Group. NHS health at work network/clinical excellence/ audit/depression and long-term sickness absence. Available from: http://www. nhshealthatwork.co.uk/depression-longterm.asp. Accessed $2014 \mathrm{Feb}$

74 First M, Williams JB, Karg RS, Spitzer RL. User's guide for the SCID-5-CV: structured clinical interview for DSM-5 disorders: clinician version A. Washington: Merican Psychiatric Association (APA) Publication; 2016.

75 Talbot F, Nouwen A, Gingras J, Bélanger A, Audet J. Relations of diabetes intrusiveness and personal control to symptoms of depression among adults with diabetes. Health Psychol. 1999;18(5):537-42.

76 de Groot M, Jacobson AM, Samson JA, Welch G. Glycemic control and major depression in patients with type 1 and type 2 diabetes mellitus. J Psychosom Res. 1999;46(5):425-35. 
77 Dunlop DD, Lyons JS, Manheim LM, Song J, Chang RW. Arthritis and heart disease as risk factors for major depression: the role of functional limitation. Med Care. 2004;42(6):50211.

78 Lustman PJ, Griffith LS, Clouse RE. Depression in adults with diabetes. Semin Clin Neuropsychiatry. 1997;2(1):15-23.

79 Egede LE, Zheng D. Independent factors associated with major depressive disorder in a national sample of individuals with diabetes. Diabetes Care. 2003;26(1):104-11.

80 Katon WJ, Von Korff M, Lin EH, Simon G, Ludman E, Russo J, et al. The Pathways Study: a randomized trial of collaborative care in $\mathrm{pa}$ tients with diabetes and depression. Arch Gen Psychiatry. 2004;61(10):1042-9.

81 Hillier TA, Pedula KL. Complications in young adults with early onset type 2 diabetes: losing the relative protection of youth. Diabetes Care. 2003;26:2999-3005.

82 Eppens MC, Craig ME, Cusumano J, Hing S, Chan AK, Howard NJ, et al. Prevalence of diabetes complications in adolescents with type 2 compared with type 1 diabetes. Diabetes Care. 2006;29(6):1300-6.

83 Pinhas-Hamiel O, Zeitler P. Acute and chronic complications of type 2 diabetes mellitus in children and adolescents. Lancet. 2007; 369(9575):1823-31.

84 Aguilar-Salinas CA, Reyes-Rodríguez E, Ordóñez-Sánchez ML, Torres MA, Ramírez-Jiménez S, Domínguez-López A, et al. Early- onset type 2 diabetes: metabolic and genetic characterization in the Mexican population. J Clin Endocrinol Metab. 2001;86(1):220-6.

85 Wong J, Molyneaux L, Constantino M, Twigg SM, Yue DK. Timing in everything: age of onset influences long term retinopathy risk in type 2 diabetes, independent of traditional risk factors. Diabetes Care. 2008;31:1985-90.

86 Chuang LM, Soegondo S, Soewondo P, Young-Seol K, Mohamed M, Dalisay E, et al. Comparisons of the outcomes on control, type of management and complications status in early onset and late onset type 2 diabetes in Asia. Diabetes Res Clin Pract. 2006;71(2): 146-55.

87 Paskov ME, Bennett PH, Knowler WC, Krakoff J, Sievers ML, Nelson RG. Effect of youthonset type 2 diabetes mellitus on incidence of end-stage renal disease and mortality in young and middle-aged Pima Indians. JAMA. 2006:296:421-6.

88 Almeida OP, McCaul K, Hankey GJ, Yeap BB, Golledge J, Norman PE, et al. Duration of diabetes and its association with depression in later life: the Health In Men Study (HIMS). Maturitas. 2016;86:3-9.

89 Lustman PJ, Anderson RJ, Freedland KE, de Groot M, Carney RM, Clouse RE. Depression and poor glycemic control: a meta-analytic review of the literature. Diabetes Care. 2000; 23(7):934-42.

90 Fisher L, Skaff MM, Mullan JT, Arean P, Mohr D, Masharani U, et al. Clinical depres- sion versus distress among patients with type 2 diabetes: not just a question of semantics. Diabetes Care. 2007;30(3):542-8.

91 Song SH, Hardisty CA. Early onset type 2 diabetes mellitus: a harbinger for complications in later years: clinical observation from a secondary care cohort. QJM. 2009;102(11):799806.

92 Lustman PJ, Griffith LS, Clouse RE. Depression in adults with diabetes. Results of 5-yr follow-up study. Diabetes Care. 1988;11(8): 605-12.

93 Rubin RR, Ma Y, Marrero DG, Peyrot M, Barrett-Connor EL, Kahn SE, et al. Elevated depression symptoms, antidepressant medicine use, and risk of developing diabetes during the diabetes prevention program. Diabetes Care. 2008;31:420-6.

94 Clouse RE, Lustman PJ, Freedland KE Griffith LS, McGill JB, Carney RM. Depression and coronary heart disease in women with diabetes. Psychosom Med. 2003;65(3): 376-83.

95 American Diabetes Association. Facilitating behavior change and well-being to improve health outcomes: standards of medical care in diabetes: 2021. Diabetes Care 2021;44(Suppl 1):S53-72.

96 Bai X, Liu Z, Li Z, Yan D, Dewen Y. The association between insulin therapy and depression in patients with type 2 diabetes mellitus: a meta-analysis. BMJ Open. 2018;8(11): $\mathrm{e} 020062$. 